\title{
Prevalence of refractive errors in school going children in district Faisalabad, Pakistan
}

\begin{abstract}
Purpose: To determine prevalence of refractive error in school going children in Faisalabad District, Pakistan

Methods: Descriptive cross-sectional study was conducted in 14 public and private schools of Faisalabad in 6 months duration from December 2018 to June 2019. 600 volunteers of both sex and age ranging between 4-15 years were studied through non-probability convenient sampling technique. Visual acuity was tested from Snellen at 6- meter distance. Retinoscopy was performed on each patient for objective analysis. Test was performed after taking complete ocular, medical, surgical and drug history. Visual acuity, extra-ocular movement, eye examination and cycloplegic refraction were done. Each eye was tested monocular and each subject was tested thrice.
\end{abstract}

Results: Our study included total 600 subjects (100\%) from which $370(61.67 \%)$ were males and $230(38.33 \%)$ were females. Prevalence of refractive errors in school going children of Faisalabad showed that prevalence of myopia is high i.e $390(51.5 \%)$ than $220(36.7 \%)$ emmetropia and 71(11.8\%) hypermetropia was in children.

Conclusion: Refractive errors are more common in school going children of Faisalabad, Pakistan. Most common refractive error seen in children was myopia than other refractive errors. Myopia is greatest public health problem for children of Faisalabad community and need of the hour is to establish mobile school camps and awareness sessions in youngsters to save ocular and related problems.

Keywords: hypermetropia, myopia, refractive errors, prevalence
Volume IO Issue I - 2020

Fatima Iqbal,' Iqra Khalil, ${ }^{2}$ Mawra Zahid ${ }^{3}$

'School of Optometry, University of Faisalabad, Pakistan

${ }^{2}$ Aziz Fatima Medical College \& Hospital, Pakistan

${ }^{3}$ The University of Lahore, Pakistan

Correspondence: Fatima lqbal, School of Optometry, University of Faisalabad, Pakistan,

Email drfatimaiqbalawan@gmail.com

Received: October 30, 2019 | Published: January 20, 2020

\section{Introduction}

Refractive error is condition in which problem with eye to properly focusing the light rays on retina as a result blurred image formed on retina. ${ }^{1}$ Normal corneal shape and curvature bent the light and focus on retina properly. But when corneal shape abnormally changed it affect the normal visual process, light not properly focus on retina and image not received clear and it causes blurring of vision. ${ }^{2}$ Some factors enhanced the refractive errors including Age, diabetes, trauma, many ocular diseases, hereditary, tv use and UV ray's exposure, use to some drugs (alcohol consumption, antihistamine and anti-depressant) that enhanced refractive errors. ${ }^{3}$ There are following types of refractive errors including emmetropia, myopia, hypermetropia and astigmatism. Emmetropia is a condition in which no error occurred and rays are clearly focused on retina and clear image formed on retina. Myopia is Also called nearsightedness is a condition in which light rays are focused in front of retina may be due to abnormal corneal structure and elongation of eye ball then average size of eye ball. Due to this patient cannot not see clear distance objects its sees blurred but near objects seen clear. It can be inherited developed in children's and early adulthood. Hypermetropia is also called farsightedness in which rays focus behind the retina so near objects are blurred but distance objects seen clear. But in case of high hypermetropia both distance and near vision is blurring. It is due shortage of length of eyeball then normal length of eyeball and abnormal shape of cornea. Astigmatism is condition in which cornea has irregular curvature. Curvature and power differ in all meridians of cornea. But has blurred vision at all distances near and far. It causes blurring of vision it is more symptomatic condition then other errors. ${ }^{4}$ Sign and Symptoms of Refractive Errors: Blur vision, squinting eye, Haloes, Glare, Headache, Eye strain and Rubbing of eyes, dizziness. ${ }^{2}$
Prevalence of refractive errors in Pakistan, Uncorrected refractive errors: $23.97 \%$ among males and $20 \%$ among females. Visually disabling refractive errors $6.89 \%$ in males and $5.71 \%$ in females. ${ }^{5}$ Total 120 million individuals are affected due to refractive errors in United States. ${ }^{6}$ Total 153 million peoples are visually impaired due to un-corrected refractive errors and 8 million are blinds in whole world. Prevalence of un-corrected refracted error was highest in low-income poor countries about $90 \%$. Rate of myopia increased due to changes in demography and living life style. Myopia increased rapidly in world from 1.95 in 2010 to 4.76 billion. ${ }^{7}$ Refractive errors also affect the economy of many countries. Worldwide annual loss of economy due to un-corrected refractive errors is $\$ 269$ billion. Above 50 years old individuals show index $\$ 121.4$ billion loss in whole world. Refractive errors are not equally distributed in countries. Myopia is more common and having more prevalence in East Asian countries. Myopia is more common in chines, Japan, Arab and Jew population countries, but less common Negroes and Sudanese population. Prevalence of hypermetropia is greater in Europe and western countries. ${ }^{8}$ Refractive errors affect children life as uncorrected refractive errors affect child daily life due to poor vision, poor cooperation to daily activities, psychological issues and leading strabismus, anisometropia and amblyopia. ${ }^{9}$

\section{Methods}

Descriptive study was conducted at 14 public and private schools of Faisalabad. 600 individuals with either gender or age ranging from 4-15 years were included in this study. Duration of study was from December 2018 to June 2019. Non-Probability Convenient sampling technique was used. Child with no any ocular disease, systemic diseases and surgical history were included in inclusion 
criteria and individuals with age less than 4 years and greater than 15 years, Ocular disease (Congenital anomalies of cornea and retina, keratoconus, keratoglobus, media opacity, aphakia, glaucoma and all retinal diseases). Dry eye, Papilledema, Down syndrome, Mar fan syndrome, Visual pathway lesions, Cataract, Diabetic ocular diseases, Trauma history were excluded in this study. After informed consent and extensive history visual acuity was checked by using Snellen visual acuity chart at 6-meter distance. Amount of refractive error were measured by doing objective refraction and later subjective along with binocular balancing. Cover uncover test used to evaluate squint. Examination included visual acuity measurements, ocular motility evaluation, cycloplegic autorefraction, and examination of the external eye, anterior segment, media and fundus. Performa was filled and data saved. Data was analyzed by using SPSS version 20 .

\section{Results}

Our study included total 600 subjects from which (61.67\%) were males and $(38.33 \%)$ were females. Prevalence of refractive errors in school going children of Tahsil Faisalabad showed that statistically out of 600 individuals' myopia is more prevalent about $51.5 \%$ than emmetropia was $36.7 \%$ and hypermetropia was $11.8 \%$ in children. No any astigmatic case was seen (Figure 1-3).

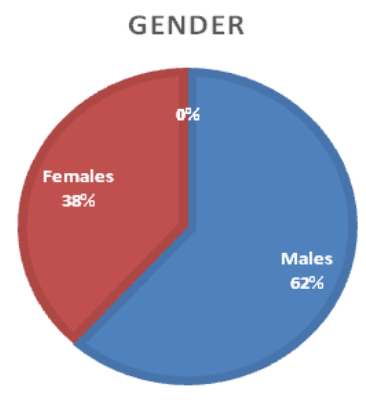

Figure I Gender Distribution. Pie chart shows frequency of gender of individuals. Total 600 patients were included in this study in which $370(62 \%)$ were males and 230(38.3\%) were females to evaluate the of refractive errors.

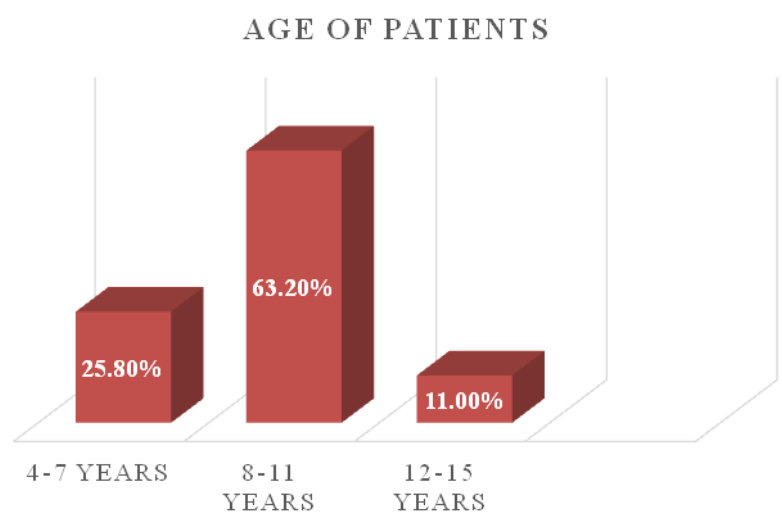

Figure 2 Age Distribution. Chart shows that, rate of different age groups.Age is divided in to three groups. Ist group included 4-7 year, 2 nd group included 8-I lyears and 3rd included 12-15 year of age. Bar chart showing that total $155(25.8 \%)$ of patients are with age $4-7$ years so group 2 nd highest rate than $2^{\text {nd }}$ group. Then 2 nd group has highest rate because $379(63.2 \%)$ patients are with age ranging from 8-II years. 3rd group has very low number of patients only 66 (II.0\%) were including in this study with age I2-I5 years.

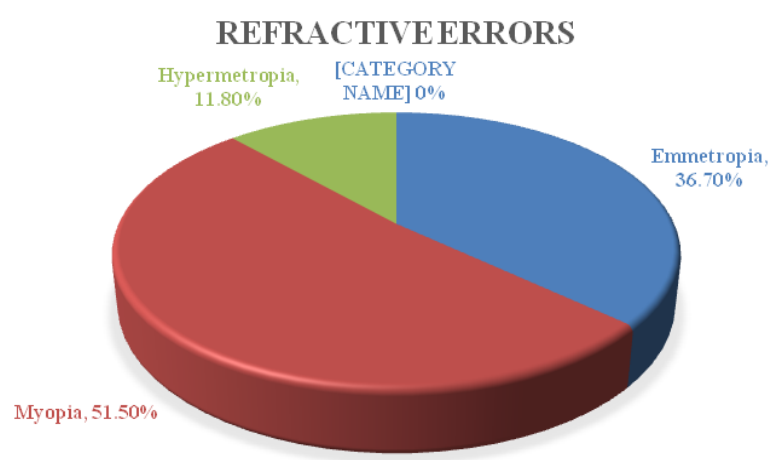

Figure 3 Frequency of refractive errors in school going children, this pie chart shows that frequency of refractive errors in school going children of tahsil Faisalabad. Out of 600 hundred patients total 390 (5I.5\%) patients were myopic, 220 (36.7\%) emmetropic and only 71 (1I.8\%) were hypermetropic. No any astigmatic patient was seen in this study.

\section{Discussion}

Refractive error is condition in which problem with eye to properly focusing the light rays on retina as a result blurred image formed on retina. There are following types of refractive errors including emmetropia, myopia, hypermetropia and astigmatism. Refractive errors are more common eye problem that found in all age groups worldwide. World health organization describe that refractive errors are responsible for visual impairment if it is not treated in time it causes visual loss. Prevalence of refractive errors in Pakistan, Uncorrected refractive errors: $23.97 \%$ among males and $20 \%$ among females. Total 120 million individuals are affected due to refractive errors in United States. We conducted study in school going children of different schools of tahsil Faisalabad to find out prevalence of refractive errors. Both genders age ranging from 4-15 were included in our study. Results of our study were shows that, Myopia is more common statistically $51.5 \%$ in Faisalabad school going children, then children were emmetropic and few numbers of students were hypermetropic. Community Based descriptive study was conducted in 2014 at Goro District, Ethiopia to evaluate Prevalence of Refractive Error and Visual Impairment Among Rural School-Age Children of Goro District. Total 570 school age children were tested. Data was analyzed by chi-square and results show that prevalence of refractive error was 3.5\% (myopia $2.6 \%$ and hyperopia $0.9 \%$ ). This study was supported our study that refractive errors especially myopia is more occurred in school going children. ${ }^{10}$

Prospective cross-sectional study was carried out on 2238 secondary school children to assess Prevalence of vision impairment and refractive error in school children in Ba Ria-Vung Tau province, Vietnam. All students were examined by testing visual acuity, eye examination fundoscopy. By using results, they concluded that myopia $20.4 \%$ greatest cause of impaired vision among school children of Vietnam. Myopia is major public health problem than other refractive errors statistically. Our study was also in favors with this study that myopia is more prevalent in school going children. ${ }^{11}$ Cross- sectional Study was conducted in 2011 to evaluate Prevalence of refractive errors among schoolchildren in rural central Ethiopia. Total 5.470 individuals were screened for refractive errors. Each subject was undergone to testing visual acuity and ocular examination. Data of 
all patients were analyzed by using chi-square. Results of this test show 405 (9.5 per cent) were visually impaired and of these 267 children were diagnosed as having refractive errors, with an overall prevalence of 6.3 per cent. Myopia is $6 \%$ and hypermetropia is $0.3 \%$ and astigmatism was 0.5 and amblyopia is $9.6 \%$. Conclusion of this study was myopia is more common than other refractive errors and commonest problem in children. Our study results also appreciated and supported to this study. ${ }^{12}$ Our study was proved that refractive errors were present in school going children. More common refractive error was myopia about $51 \%$ in tahsil Faisalabad. Another Study was conducted on total 1000 students in Karachi, Pakistan to find out prevalence of refractive errors. Total 100 students of Board of Secondary Education and 20 schools were randomly selected from the list in the five districts of Karachi for this study. All students were examined or screened for refractive errors. Results of this study were $8.9 \%$ refractive errors were present in children. They concluded that increased in refractive errors were seen in children. ${ }^{13}$

\section{Conclusion}

Myopia (Near-sightedness) is seen more obviously in school going children in Faisalabad, Pakistan. Myopia is greatest public health problem for children of Asian community due to lack of screening programs at Schools, lack of education in teachers and parents, excessive near work, deprived classroom lighting facilities and outdoor activities and use of electronic gadgets. There is a need of periodical eye examination and need for regular school-screening programs that provide glasses at low cost or free of charge for those who have refractive errors to prevent for increased rate of refractive errors in children. Moreover, awareness campaigns and education can help to overcome visual problems.

\section{Acknowledgments}

None.

\section{Conflicts of interest}

Authors don't have any conflict of interest.

\section{Funding}

Authors don't have any financial disclosure.

\section{References}

1. WHO. What is a refractive error? 2013.

2. National Eye Institute. Facts about Refractive Errors. 2010.

3. Department of Health. 5.3 Refractive error. 2008.

4. Very well health. Troy L Bedinghaus OD. 2017.

5. Abdullah AS, Jadoon MZ, Akram M. Prevalence of uncorrected refractive errors in adults aged 30 years and above in a rural population in pakistan. J Ayub Med Coll Abbottabad. 2015;27(1):8-12.

6. National Eye Institute. Facts about Refractive Errors. 2019.

7. Uncorrected Refractive Error: A Mounting Challenge. 2019.

8. Hashemi H, Fotouhi A, Yekta A, et al. Global and regional estimates of prevalence of refractive errors: Systematic review and meta-analysis. $J$ Curr Ophthalmol. 2017;30(1):3-22.

9. Kilic-Toprak E, Toprak I. Future Problems of Uncorrected Refractive Errors in Children. Procedia-Social and Behavioral Sciences. 2014;159:534-536.

10. Kedir J, Girma A. Prevalence of Refractive Error and Visual Impairment among Rural School-Age Children of Goro District, Gurage Zone, Ethiopia. Ethiop J Health Sci. 2014;24(4):353.

11. Paudel P, Ramson P, Naduvilath T, et al. Prevalence of vision impairment and refractive error in school children in Ba Ria - Vung Tau province, Vietnam. Clin Exp Ophthalmol. 2014;42(3):217-226.

12. Mehari ZA, Yimer AW. Prevalence of refractive errors among schoolchildren in rural central Ethiopia. Clinical and Experimental Optometry. 2012;96(1):65-69.

13. Alam H, Siddiqui M, Jafri S, et al. Prevalence of refractive error in school children of Karachi. J Pak Med Assoc. 2008;58(6):322-325. 